\title{
Neuroblastoma in Saudi Children: A Single Center Experience (2006-2014)
}

\author{
Zaid Al Naqib1 ${ }^{*}$, Atif A. Ahmed1,2, Musa Al Harbi1, Fahad Al Manjomi1, Zaheer Ullah Khan1, \\ Awatif Alanazi1, Othman Mosleh', Walid Ballourah', Mohammed Rayis' \\ ${ }^{1}$ Pediatric Hematology/Oncology Division, King Fahad Medical City, Riyadh, Saudi Arabia \\ ${ }^{2}$ Department of Pathology and Laboratory Medicine, Children's Mercy Hospital, Kansas City, USA \\ Email: ${ }^{*}$ znaqib@gmail.com
}

Received 20 August 2015; accepted 19 September 2015; published 22 September 2015

Copyright (C) 2015 by authors and Scientific Research Publishing Inc.

This work is licensed under the Creative Commons Attribution International License (CC BY). http://creativecommons.org/licenses/by/4.0/

cc) (i) Open Access

\section{Abstract}

Introduction: Neuroblastoma is the most common extracranial solid tumor in childhood and survival rate has improved during the last few decades. Only a few studies, related to Neuroblastoma in Saudi Arabian children, have been performed. We report epidemiologic data and our clinical experience from the department of Pediatric Hematology Oncology (PHO), King Fahad Medical City (KFMC), Riyadh, Saudi Arabia. Method: A retrospective observational study of all patients, with diagnosis of Neuroblastoma, who attended PHO-KFMC from July 2006 to June 2014 was performed. The survival periods (overall survival and disease-free survival) and the final outcomes for patients treated and followed at KFMC were recorded. The survival data were statistically correlated with the clinical, pathological and biological features of patients and tumors and compared to national and international cohorts. Results: Eight-year data were available for the 42 patients of which $22(52.4 \%)$ were male and $20(47.6 \%)$ were females. Age at diagnosis ranged 0 - 91 months with a mean and median of 26.3 and 18.5 months respectively. $16(38.1 \%)$ patients were under one year and $26(61.9 \%)$ above 1 year of age. The event-free survival (EFS) and overall survival (OS) rates were $66.5 \%$ and $71.5 \%$ respectively. EFS and $O S$ among those who were $<1$ year age at presentation was $75 \%$ and $82 \%$, whereas $\geq 1$ yr age group had $59 \%$ and $62 \%$ survival rates respectively. Patients with tumors in the adrenal had considerably lower EFS (59\%) and OS (63\%); in comparison to patients with tumors sites other than the adrenal who had EFS and OS of $85 \%$ and $89 \%$ respectively. Both EFS and OS survival rates at the end of follow-up interval were $100.0 \%$, in the low and intermediate risk groups. In contrast, patients in the high risk group had EFS and OS rates of $44 \%$ and $48 \%$ respectively. This difference was statistically significant $(p<0.05)$. Conclusion: Our results are very encouraging and comparable with known published international cohorts, and reveal an excellent outcome for stage $1,2,3 \& 4 \mathrm{~s}$. The prognosis for advanced (stage 4) disease remains rather poor. A collaborative Saudi-wide effort, with an emphasis on research in detecting clinical and biologic characteristics of aggressive disease and tailoring therapy, is needed.

${ }^{*}$ Corresponding author.

How to cite this paper: Al Naqib, Z., Ahmed, A.A., Al Harbi, M., Al Manjomi, F., Khan, Z.U., Alanazi, A., Mosleh, O., Ballourah, W. and Rayis, M. (2015) Neuroblastoma in Saudi Children: A Single Center Experience (2006-2014). Journal of Cancer Therapy, 6, 896-905. http://dx.doi.org/10.4236/jct.2015.610098 


\section{Keywords}

\section{Children, Neuroblastoma, Saudi Arabia, Survival}

\section{Introduction}

Neuroblastoma (NBL) is the most common malignant extracranial solid tumor in the pediatric population, accounting for approximately $8 \%-10 \%$ of all childhood malignancies and about 8.7 million cases per year. It primarily affects children younger than 10 years of age. Nearly $50 \%$ of patients are below the age of 2 years. NBL is slightly more prevalent in boys than in girls (1.2:1 ratio). The majority of patients (almost 70\% of cases), have an abdominal primary, (45\% in adrenal medulla and 25\% in sympathetic ganglia) [1].

The 5-year event free survival (EFS) for high-risk Neuroblastoma remains rather disappointing, with less than $50 \%$ of children with stage 4 NBL being alive after 5 years, despite intensive multimodality therapy. The best outcome recently reported for high-risk NBL was achieved with intensive combination induction chemotherapy and surgery, followed by myeloablative therapy, hematopoietic stem cell rescue, and then differentiation therapy [2]. Age, stage and amplification of the MYCN oncogene are the most validated prognostic markers [3] [4]. Recent research has shed light on the biology of NBL allowing more accurate stratification of patients, which has permitted withholding cytotoxic therapy without affecting outcome for low-risk patients. However, patients with high risk disease await the development of new therapy that is necessary for cure [5]. Current evidence does not support Neuroblastoma screening. Mass screening programs have been tried in several countries, with differing screening tools, including screening at the ages of 3 weeks, 6 months, and/or 1 year. However these programs have not resulted in a reduction in the incidence of advanced-stage NB with unfavorable biological characteristics in older children, there has not been a reduction in the number of deaths from NBL in infants screened at any age [6]-[9] and no public health benefits have been shown from screening infants for Neuroblastoma at these ages.

They are very few studies on Neuroblastoma that were undertaken in Saudi Arabia. A systematic search of the MEDLINE database from 1994 to 2014, and the Cochrane Library limited to English language articles using the terms "Neuroblastoma and Saudi Arabia” was conducted to identify all publications on Neuroblastoma in Saudi Arabian Children. 20 potentially relevant papers were identified. Of these only three papers relevant to this study were selected and reviewed. One paper, published in 1998 was a retrospective, single center study of the outcome of 20 patients in the Eastern region [10]. A second paper analyzed the outcome of 43 children with Neuroblastoma with a special emphasis on the rate and duration of remission in children with disseminated Neuroblastoma [11] and a third retrospectively reviewed 75 patients with Neuroblastoma treated at King Abdul-Aziz Medical City, Jeddah, Kingdom of Saudi Arabia between 1986 and 2005, with emphasis on the outcome of patients with stage $4 \mathrm{~S}$ Neuroblastoma [12]. It is evident, from the aforementioned literature search, that, in spite of the great advances that Saudi Arabia has made in the care of children with cancer. We are lacking data on the incidence and prevalence of Neuroblastoma in Saudi Arabian children.

\section{Materials and Methods}

Aims: The primary aim was to assess survival trends (overall survival and disease-free survival) and final outcomes for Neuroblastoma patients treated at KFMC, correlate the survival data with the clinical, pathological and biological features of the tumor and compare findings to national and international cohorts. A secondary aim was to set up a local database for our growing number of patients with NBL.

Study design: A retrospective observational cohort study. Electronic record review of 42 patients diagnosed with Neuroblastoma and ganglioneuroblastoma who attended KFMC period July 2006 to June 2014 was carried out. Two cases of ganglioneuroma were also included. After Institutional Review Board (IRB) approval was obtained, patients data was extracted from the hospital computer system (CORTTEX, CENTRICITY \& HIM), which allowed extraction of medical, radiological and laboratory data and pharmaceutical prescriptions. Data was then recorded on a comprehensive excel sheet.

Patients: A diagnosis of Neuroblastoma was made based on the histopathology obtained from the primary tumor or metastatic sites, such as bone marrow specimen. International Neuroblastoma Pathology Classification 
(INPC) and disease staging, in accordance with the International Neuroblastoma Staging System (INSS), was performed based on the clinicopathologic features. The size and location of the primary tumors were defined by imaging studies using computed tomography (CT) or magnetic resonance (MR) imaging. Metastatic disease was further investigated by bone marrow aspiration and biopsies from at least two sites in the iliac crests, as well as additional imaging with 131I metaiodobenzylguanidine (MIBG) and 99mTechnetium bone imaging. Positive disease findings were monitored serially by further imaging studies for treatment response. Patients were treated according to their assigned risk group (low, intermediate and high risk) and per the Children's Oncology Group (COG)-based protocols. Complete remission was defined as the absence of any evidence of disease on any imaging modality (CT, MR imaging, MIBG or bone scintiscan) and bone marrow studies.

Other clinical date: Degree of surgical intervention, serum levels of lactate dehydrogenase and catecholamine levels in the urine were recorded. Cytogenetic studies of the MYCN gene amplification status were performed by in situ hybridization in 39 of the 42 patients. Tests for 1p deletion, $17 q$ gain and DNA ploidy were not available at our institute during the study duration and were not performed.

Statistical Analysis: All normally distributed data was presented as mean \pm SEM (standard error of the mean). Independent samples t-test was carried out to compare values between two groups. A two-sided $\alpha$ level of 0.05 was used for assessing statistical significance. Statistical analysis was performed using SPSS for Windows, and association between variables was determined by the Pearson correlation coefficient. Descriptive analysis was used to summarize patient characteristics. Non-parametric variables were described by medians and ranges while categorical variables were expressed by frequency. Chi-square and/or Fisher Exact tests were carried out for comparison of values between two categorical variables.

\section{Results}

\subsection{Patients Characteristics}

Eight-year data was available for the 42 patients with Neuroblastoma, of which 22 (52.5\%) were male and 20 (47.6\%) were female. Age at diagnosis ranged from 0 to 91 months, with mean and median of $26.3 \pm 3.7$ and 18.5 months respectively. Moreover, 16 (38.1\%) patients were under one year and 26 (61.9\%) above 1 year of age (Table 1, Table 2). The age difference across gender was not statistically significant.

INSS risk assessment was low in 11 (26.2\%), intermediate in 11 (26.2\%) and high in 20 (47.6\%) patients. Follow-up was terminated at 96 months during which 11 (100\%) low risk, 11 (100\%) intermediate risk and 12 $(60.0 \%)$ high risk patients had survived. Overall survival time was $30.9 \pm 4.5(1,96)$ months during which 34 (81.0\%) patients survived by the terminating point and the disease free survival time was $25.4 \pm 4.3$ (0, 92 ) months.

Tumors among male patients were located in the adrenal and retroperitoneum in 17 (77.3\%) and 5 (22.7\%) respectively, of which 15 (68.2\%) had INSS stage 3 and 4. Five distinct tumor sites were noted among females: Adrenal 9 (45.0\%), retroperitoneal 4 (20\%), paravertebral 3 (15\%), mediastinum 2 (10\%) and liver 2 (10\%); of which 17 (85\%) had INNS stage 3 and 4. Gross total resection, partial resection and biopsy were the extent of surgical intervention in 24 (57.1\%), 5 (11.9\%) and 12 (28.6\%) patients respectively.

\subsection{Pathology and Laboratory Studies}

Schwannian stroma-poor Neuroblastoma was diagnosed in 34 (81.0\%) patients, of whom 20 (90.9\%) were males and 14 (70\%) were females. Ganglioneuroblastoma was diagnosed in 6 (14.3\%) patients, 5 (25\%) of whom were females. Ganglioneuroma was diagnosed in 2 (4.8\%) patients; one from each gender. 10 patients (23.8\%) had MYCN amplification. 26 patients (61.9\%) had a favorable histology according to the INPC. Lactate dehydrogenase (LDH) serum level had reference range value of $1287.8 \pm 264.1 \mathrm{U} / \mathrm{l}(\mathrm{N} 135$ - $225 \mathrm{U} / \mathrm{l})$ and ranged between 269 and $7666 \mathrm{U} / \mathrm{l}$ for all patients. Urine catecholamines were raised in 23 (54.8\%) patients.

\subsection{Survival Analysis}

Patients were followed up for eight years. By the end of the study we had 8 patients who died (19\%) and 34 patients (81\%) are still alive. The overall survival (OS) and event-free survival (EFS) rates were $71.5 \%$ and $66.5 \%$ respectively. Males and females had OS of $71.0 \%$ and $75.0 \%$, whereas the EFS was $66.0 \%$ and $67.0 \%$ respectively. There were 16 patients $<1$ year of age, of whom 15 survived (93\%); and 26 patients were $>1$ year of age 
Table 1. Patients characteristics.

\begin{tabular}{|c|c|c|c|c|c|c|c|c|c|}
\hline & & \multicolumn{2}{|c|}{ Survived } & \multicolumn{2}{|c|}{ Died } & \multicolumn{2}{|c|}{ Overall Survival (OS) } & \multicolumn{2}{|c|}{$\begin{array}{l}\text { Event Free Survival } \\
\text { (EFS) }\end{array}$} \\
\hline & & $\mathrm{n}$ & $\%$ & $\mathrm{n}$ & $\%$ & OS & HR (95\% CI) & EFS & HR (95\% CI) \\
\hline \multirow{2}{*}{ Gender } & Female & 16 & 80.0 & 4 & 20.0 & 75.0 & \multirow{2}{*}{$\begin{array}{c}1.05 \\
(0.26 \text { to } 4.25)\end{array}$} & 67.0 & \multirow{2}{*}{$\begin{array}{c}1.02 \\
(0.25 \text { to } 4.08)\end{array}$} \\
\hline & Male & 18 & 81.8 & 4 & 18.2 & 71.0 & & 66.0 & \\
\hline \multirow{3}{*}{ Age (yr) } & $<1 \mathrm{yr}$ & 15 & 93.8 & 1 & 6.3 & 82.0 & \multirow{2}{*}{$\begin{array}{c}0.18 \\
(0.02 \text { to } 1.51)\end{array}$} & 75.0 & \multirow{2}{*}{$\begin{array}{c}0.19 \\
(0.02 \text { to } 1.52)\end{array}$} \\
\hline & $\geq 1 \mathrm{yr}$ & 19 & 73.1 & 7 & 26.9 & 62.0 & & 59.0 & \\
\hline & median (min, max) & 16.0 & 0, 91) & 27. & ,65) & & & & \\
\hline \multirow{2}{*}{ Tumor location } & Others & 15 & 93.8 & 1 & 6.3 & 89.0 & \multirow{2}{*}{$\begin{array}{c}0.24 \\
(0.03 \text { to } 1.95)\end{array}$} & 85.0 & \multirow{2}{*}{$\begin{array}{c}0.21 \\
\text { (0.02 to } 1.68)\end{array}$} \\
\hline & Adrenal & 19 & 73.1 & 7 & 26.9 & 63.0 & & 55.0 & \\
\hline \multirow{3}{*}{ Diagnosis } & Ganglioneuroma & 2 & 100.0 & 0 & 0 & 100.0 & & 100.0 & \\
\hline & Ganglioneuroblastoma & 4 & 66.7 & 2 & 33.3 & 48.0 & & 24.0 & \\
\hline & Neuroblastoma & 28 & 82.4 & 6 & 17.6 & 74.0 & $\begin{array}{c}2.64 \\
\text { (0.51 to } 13.67 \text { ) }\end{array}$ & 70.0 & $\begin{array}{c}2.45 \\
\text { (0.47 to } 12.67)\end{array}$ \\
\hline \multirow{4}{*}{ LDH Grade } & $<5 *$ Normal & 25 & 89.3 & 3 & 10.7 & 73.0 & \multirow{2}{*}{$\begin{array}{c}0.26 \\
(0.06 \text { to } 1.10)\end{array}$} & 73.0 & \multirow{2}{*}{$\begin{array}{c}0.26 \\
\text { (0.06 to } 1.10)\end{array}$} \\
\hline & $>5 *$ Normal & 8 & 61.5 & 5 & 38.5 & 53.0 & & 53.0 & \\
\hline & median (min, max) & \multicolumn{2}{|c|}{$\begin{array}{c}480.0 \\
(269,5963)\end{array}$} & \multicolumn{2}{|c|}{$\begin{array}{c}1405.5 \\
(315,7666)\end{array}$} & & & & \\
\hline & Negative & 10 & 90.9 & 1 & 9.1 & 90.0 & & 88.0 & \\
\hline \multirow{2}{*}{$\begin{array}{c}\text { Urine } \\
\text { Catecholeamines }\end{array}$} & Positive & 19 & 82.6 & 4 & 17.4 & 60.0 & $\begin{array}{c}0.16 \\
\text { (0.02 to } 1.59)\end{array}$ & 54.0 & $\begin{array}{c}0.13 \\
\text { (0.01 to } 1.31)\end{array}$ \\
\hline & Not done & 5 & 62.5 & 3 & 37.5 & 48.0 & $\begin{array}{c}0.46 \\
\text { (0.10 to } 2.06)\end{array}$ & 32.0 & $\begin{array}{c}0.43 \\
\text { (0.10 to } 1.94)\end{array}$ \\
\hline \multirow{3}{*}{ Stage (INSS) } & Stage 4S, 1 \& 2 & 10 & 100.0 & 0 & 0 & 100.0 & \multirow{2}{*}{$\begin{array}{c}0.03 \\
(0.00 \text { to } 20.73)\end{array}$} & 100.0 & \multirow{2}{*}{$\begin{array}{c}0.03 \\
(0.00 \text { to } 33.18)\end{array}$} \\
\hline & Stage $3 \& 4$ & 24 & 75.0 & 8 & 25.0 & 64.0 & & 59.0 & \\
\hline & Not Amplified & 23 & 88.5 & 3 & 11.5 & 72.0 & & 62.0 & \\
\hline \multirow[t]{2}{*}{ MYCN Status } & Amplified & 7 & 70.0 & 3 & 30.0 & 70.0 & $\begin{array}{c}0.45 \\
(0.07 \text { to } 2.69)\end{array}$ & 66.0 & $\begin{array}{c}0.46 \\
\text { (0.07 to } 2.80)\end{array}$ \\
\hline & Not done & 4 & 66.7 & 2 & 33.3 & 64.0 & $\begin{array}{c}1.11 \\
\text { (0.18 to } 6.77)\end{array}$ & 61.0 & $\begin{array}{c}1.17 \\
(0.19 \text { to } 7.10)\end{array}$ \\
\hline \multirow{2}{*}{$\begin{array}{c}\text { Tumor } \\
\text { Differentiation }\end{array}$} & Differentiated & 5 & 71.4 & 2 & 28.6 & 74.0 & \multirow{2}{*}{$\begin{array}{c}0.64 \\
\text { (0.15 to } 2.69)\end{array}$} & 74.0 & \multirow{2}{*}{$\begin{array}{c}0.68 \\
\text { (0.16 to } 2.92)\end{array}$} \\
\hline & Undifferentiated & 9 & 90.0 & 1 & 10.0 & 71.0 & & 65.0 & \\
\hline \multirow{2}{*}{ INPC } & Unfavorable Histology & 12 & 85.7 & 2 & 14.3 & 84.0 & \multirow{2}{*}{$\begin{array}{c}0.63 \\
(0.13 \text { to } 3.15)\end{array}$} & 81.0 & 0.68 \\
\hline & Favorable Histology & 20 & 76.9 & 6 & 23.1 & 61.0 & & 52.0 & (0.14 to 3.41$)$ \\
\hline & Low Risk & 11 & 100.0 & 0 & 0 & 100.0 & & 100.0 & \\
\hline $\begin{array}{l}\text { INSS Risk } \\
\text { Assessment }\end{array}$ & Intermediate Risk & 11 & 100.0 & 0 & 0 & 100.0 & $\begin{array}{c}0.01 \\
\text { (0.00 to } 35.04)\end{array}$ & 100.0 & $\begin{array}{c}0.01 \\
(0.00 \text { to } 66.06)\end{array}$ \\
\hline & High Risk & 12 & 60.0 & 8 & 40.0 & 48.0 & $\begin{array}{c}0.01 \\
\text { (0.00 to 55.69) }\end{array}$ & 44.0 & $\begin{array}{c}0.01 \\
(0.00 \text { to } 33.14)\end{array}$ \\
\hline
\end{tabular}


Table 2. Patients characteristics based on risk group.

\begin{tabular}{|c|c|c|c|c|c|c|c|c|}
\hline & & \multicolumn{2}{|c|}{ Low Risk } & \multicolumn{2}{|c|}{ Intermediate Risk } & \multicolumn{2}{|c|}{ High Risk } & \multirow{2}{*}{$\mathrm{p}$ value } \\
\hline & & $\mathrm{n}$ & $\%$ & $\mathrm{n}$ & $\%$ & $\mathrm{n}$ & $\%$ & \\
\hline \multirow{2}{*}{ Gender } & Female & 1 & 5.0 & 10 & 50.0 & 9 & 45.0 & \multirow{2}{*}{$>0.05$ (NS) } \\
\hline & Male & 7 & 31.8 & 7 & 31.8 & 8 & 36.4 & \\
\hline \multirow{3}{*}{ Age (yr) } & $<1 \mathrm{yr}$ & 7 & 43.8 & 9 & 56.3 & 0 & .0 & \multirow{2}{*}{$<0.05$ (Sig) } \\
\hline & $\geq 1 \mathrm{yr}$ & 1 & 3.8 & 8 & 30.8 & 17 & 65.4 & \\
\hline & Median (min, max) & \multicolumn{2}{|c|}{$4.0(0,15)$} & \multicolumn{2}{|c|}{$11.0(2,91)$} & \multicolumn{2}{|c|}{$26.0(14,75)$} & $<0.05$ (Sig) \\
\hline \multirow{5}{*}{ Tumor location } & Mediastinum & 0 & 0 & 1 & 50.0 & 1 & 50.0 & \multirow{5}{*}{$>0.05$ (NS) } \\
\hline & Retroperitoneal & 1 & 11.1 & 5 & 55.6 & 3 & 33.3 & \\
\hline & Adrenal & 7 & 26.9 & 6 & 23.1 & 13 & 50.0 & \\
\hline & Liver & 0 & 0 & 2 & 100.0 & 0 & .0 & \\
\hline & Paravertebral & 0 & 0 & 3 & 100.0 & 0 & .0 & \\
\hline \multirow{3}{*}{ Diagnosis } & Ganglioneuroma & 0 & 0 & 2 & 100.0 & 0 & .0 & \multirow{3}{*}{$>0.05$ (NS) } \\
\hline & Ganglioneuroblastoma & 0 & 0 & 4 & 66.7 & 2 & 33.3 & \\
\hline & Neuroblastoma & 8 & 23.5 & 11 & 32.4 & 15 & 44.1 & \\
\hline \multirow{7}{*}{ LDH Grade } & Not done & 1 & 100.0 & 0 & 0 & 0 & 0 & \multirow{6}{*}{$<0.05$ (Sig) } \\
\hline & $>1 *$ Normal & 7 & 38.9 & 8 & 44.4 & 3 & 16.7 & \\
\hline & $>2 *$ Normal & 0 & 0 & 5 & 83.3 & 1 & 16.7 & \\
\hline & $>3 *$ Normal & 0 & 0 & 2 & 66.7 & 1 & 33.3 & \\
\hline & $>4 *$ Normal & 0 & 0 & 1 & 100.0 & 0 & 0 & \\
\hline & $>5 *$ Normal & 0 & 0 & 1 & 7.7 & 12 & 92.3 & \\
\hline & Median (min, max) & \multicolumn{2}{|c|}{$\begin{array}{c}315.0 \\
(272,446)\end{array}$} & \multicolumn{2}{|c|}{$\begin{array}{c}480.0 \\
(269,7666)\end{array}$} & \multicolumn{2}{|c|}{$\begin{array}{c}1452.0 \\
(315,5963)\end{array}$} & $<0.05$ (Sig) \\
\hline \multirow{3}{*}{ Urine catecholamines } & Negative & 1 & 9.1 & 5 & 45.5 & 5 & 45.5 & \multirow{3}{*}{$>0.05$ (NS) } \\
\hline & Positive & 5 & 21.7 & 10 & 43.5 & 8 & 34.8 & \\
\hline & Not done & 2 & 25.0 & 2 & 25.0 & 4 & 50.0 & \\
\hline \multirow{4}{*}{ Extent of surgery } & Biopsy & 1 & 8.3 & 7 & 58.3 & 4 & 33.3 & \multirow{4}{*}{$>0.05$ (NS) } \\
\hline & Gross Total Resection & 7 & 29.2 & 7 & 29.2 & 10 & 41.7 & \\
\hline & Partial Resection & 0 & 0 & 3 & 60.0 & 2 & 40.0 & \\
\hline & Not done & 0 & 0 & 0 & 0 & 1 & 100.0 & \\
\hline \multirow{3}{*}{ ASCT } & Yes & 0 & 0 & 1 & 8.3 & 11 & 91.7 & \multirow{3}{*}{$<0.05$ (Sig) } \\
\hline & No & 8 & 29.6 & 16 & 59.3 & 3 & 11.1 & \\
\hline & Not done & 0 & 0 & 0 & 0 & 3 & 100.0 & \\
\hline Sningl Jnyolyomont & Yes & 0 & 0 & 4 & 100.0 & 0 & .0 & $\leq 005$ (Siه) \\
\hline 与р & No & 8 & 21.1 & 13 & 34.2 & 17 & 44.7 & - \\
\hline & Negative & 3 & 60.0 & 2 & 40.0 & 0 & .0 & \\
\hline $\begin{array}{l}\text { Metaiodobenzyl-guanidine } \\
\text { (mIBG) scan }\end{array}$ & Positive & 5 & 13.9 & 14 & 38.9 & 17 & 47.2 & $>0.05$ (NS) \\
\hline & Not done & 0 & 0 & 1 & 100.0 & 0 & 0 & \\
\hline
\end{tabular}




\begin{tabular}{|c|c|c|c|c|c|c|c|c|}
\hline \multicolumn{9}{|l|}{ Continued } \\
\hline \multirow{5}{*}{$\begin{array}{l}\text { Stage } \\
\text { (INSS) }\end{array}$} & Stage 4S & 3 & 60.0 & 2 & 40.0 & 0 & 0 & \multirow{5}{*}{$<0.05$ (Sig) } \\
\hline & Stage 1 & 4 & 100.0 & 0 & 0 & 0 & 0 & \\
\hline & Stage 2 & 1 & 100.0 & 0 & 0 & 0 & 0 & \\
\hline & Stage 3 & 0 & 0 & 12 & 92.3 & 1 & 7.7 & \\
\hline & Stage 4 & 0 & 0 & 3 & 15.8 & 16 & 84.2 & \\
\hline \multirow{3}{*}{$\begin{array}{l}\text { MYCN gene } \\
\text { Status }\end{array}$} & Amplified & 0 & 0 & 0 & .0 & 10 & 100.0 & \multirow{3}{*}{$<0.05$ (Sig) } \\
\hline & Not Amplified & 7 & 26.9 & 15 & 57.7 & 4 & 15.4 & \\
\hline & Not done & 1 & 16.7 & 2 & 33.3 & 3 & 50.0 & \\
\hline \multirow{3}{*}{ INPC } & Favorable Histology & 8 & 30.8 & 14 & 53.8 & 4 & 15.4 & \multirow{3}{*}{$<0.05$ (Sig) } \\
\hline & Unfavorable Histology & 0 & 0 & 2 & 14.3 & 12 & 85.7 & \\
\hline & Unknown & 0 & 0 & 1 & 50.0 & 1 & 50.0 & \\
\hline \multirow{2}{*}{ Outcome } & Survived & 8 & 23.5 & 15 & 44.1 & 11 & 32.4 & \multirow{2}{*}{$>0.05$ (NS) } \\
\hline & Died & 0 & 0 & 2 & 25.0 & 6 & 75.0 & \\
\hline Overall Survival (month) & Median (min, max) & \multicolumn{2}{|c|}{$29.5(8,96)$} & \multicolumn{2}{|c|}{$15.0(5,86)$} & \multicolumn{2}{|c|}{$14.0(1,93)$} & $>0.05$ (NS) \\
\hline Disease Free Survival (month) & Median (min, max) & \multicolumn{2}{|c|}{$28.0(5,92)$} & \multicolumn{2}{|c|}{$12.0(0,86)$} & \multicolumn{2}{|c|}{$12.0(1,87)$} & $>0.05$ (NS) \\
\hline
\end{tabular}

NS: Not significant; Sig: Significant; ASCT: Autologous Stem Cell Transplantation.

of, whom 19 patients survived (73\%) and 7 died (26\%). The OS and EFS among $<1$ year age at presentation was $82 \%$ and $75 \%$, whereas the $\geq 1$ yr age group had $62 \%$ and $59 \%$ survival rates respectively.

There were 26 patients (62\%) with adrenal primary, of whom 7 patients (26.9\%) died, in contrast to the nonadrenal primary tumors (16 patients), of whom only one patient died (6\%). Adrenal tumor patients had considerable low OS (63.0\%) and EFS (59.0\%) while patients with other-than-adrenal tumor sites had OS and EFS of $89 \%$ and $85 \%$ respectively. Patients with INSS stages (4S, 1 \& 2) had 100.0\% OS and EFS whereas those with advanced stages (stages 3 and 4 ) had 64\% OS and 59\% EFS.

LDH was elevated in all the subjects of whom 13 (31.0\%) had levels five times more than the normal (LDH > $5 \mathrm{~N}$ ). OS and EFS among LDH > $5 \mathrm{~N}$ patients was $60 \%$ and $53 \%$, while other subjects had rates of $77 \%$ and $73 \%$ respectively. OS and EFS among patients with amplified MYCN tumors was 70\% and 66\% whereas patients with non-amplified MYCN tumors had $72 \%$ and $62 \%$.

Disease free survival rate at the end of the follow-up interval in the low risk group was $100.0 \%$, in the intermediate risk group was $100.0 \%$ and in the high risk group $44 \%$. The difference was significant $(p<0.05)$ (Figure 1). Similarly, the overall survival rate at the end of interval in the low risk group was $100.0 \%$, in the intermediate risk group was $100.0 \%$ and in the high risk group 48\%. The difference was also significant (p < 0.05$)$ (Figure 2). INSS Low Risk and Intermediate Risk patients had corresponding OS and EFS of 100\% each while High Risk patients had OS of 48\% and EFS of 44\%. INSS Stage 4S was observed in 5 (11.9\%) patients, of whom 4 (80\%) patients were categorized as low risk and 1 (20\%) as intermediate risk; and all of them 5 (100\%) had survived at termination of study. Stage 1 was observed in 4 (9.5) patients, all of them 4 (100\%) had survived at termination of study. Stage 2 was observed in $1(2.7 \%)$ patient, who was intermediate risk and had survived at the termination of study. Stage 3 was observed in 13 (31\%) patients of whom 4 (30.8\%) were low risk, 7 (53.8\%) intermediate risk and 2 (15.4\%) high risk. Mortality occurred in 1 (7.3\%) patient with stage 3 disease among the high risk group. Stage 4 was observed in 19 (45.2\%) patients of whom 2 (10.5\%) were intermediate risk and 17 (89.5\%) were high risk. Of the latter, mortality occurred in 7 (41.2\%) patients. Mortality occurred in stage 3 and stage 4 disease subjects only, and that resulted in subsequent survival rate of $92.3 \%$ among stage 3 and $63.2 \%$ among stage 4 patients.

EFS among, stage 1,stage 2 and stage 4S disease subjects was $100.0 \%$ each, whereas stage 3 had $83 \%$ and stage 4 had 51\% respectively (Figure 3). OS among stage 4S, stage 1 and stage 2 disease subjects was $100.0 \%$ each, whereas stage 3 had 90\% and stage 4 53\% rate, respectively (Figure 4). 


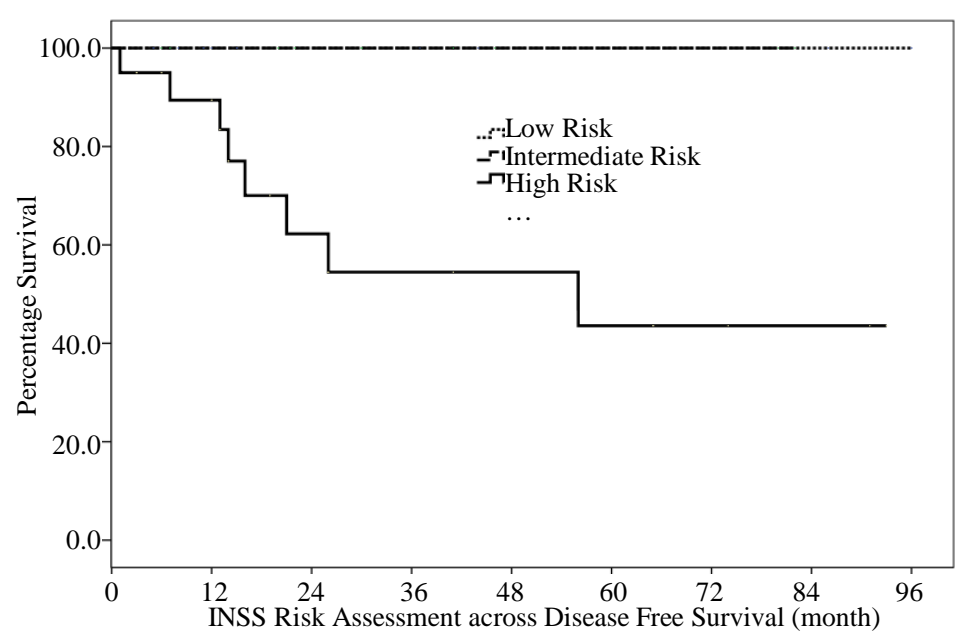

Figure 1. INSS risk assessment across disease free survival (months).

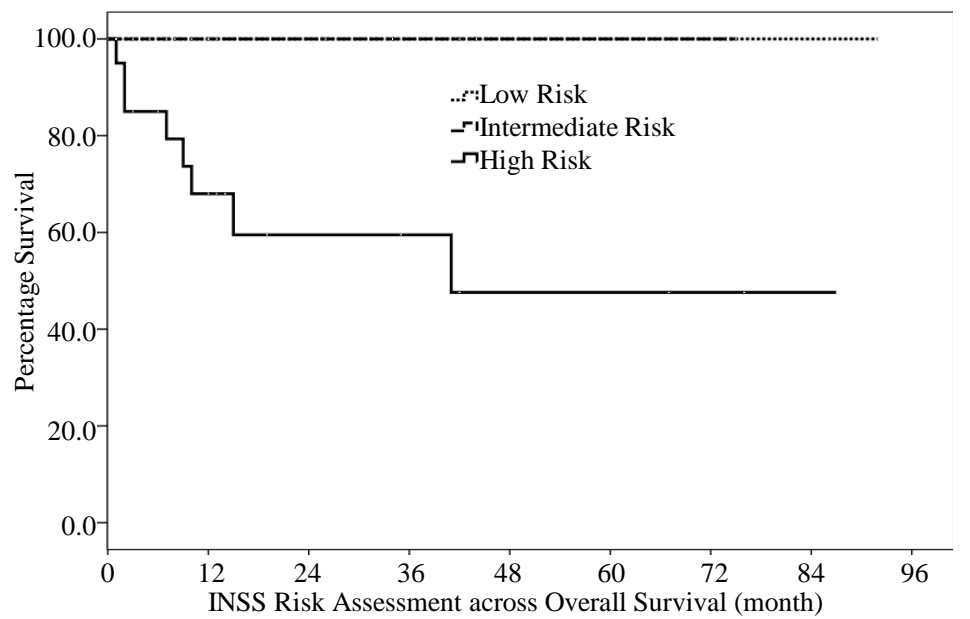

Figure 2. INSS Risk Assessment across overall survival (months).

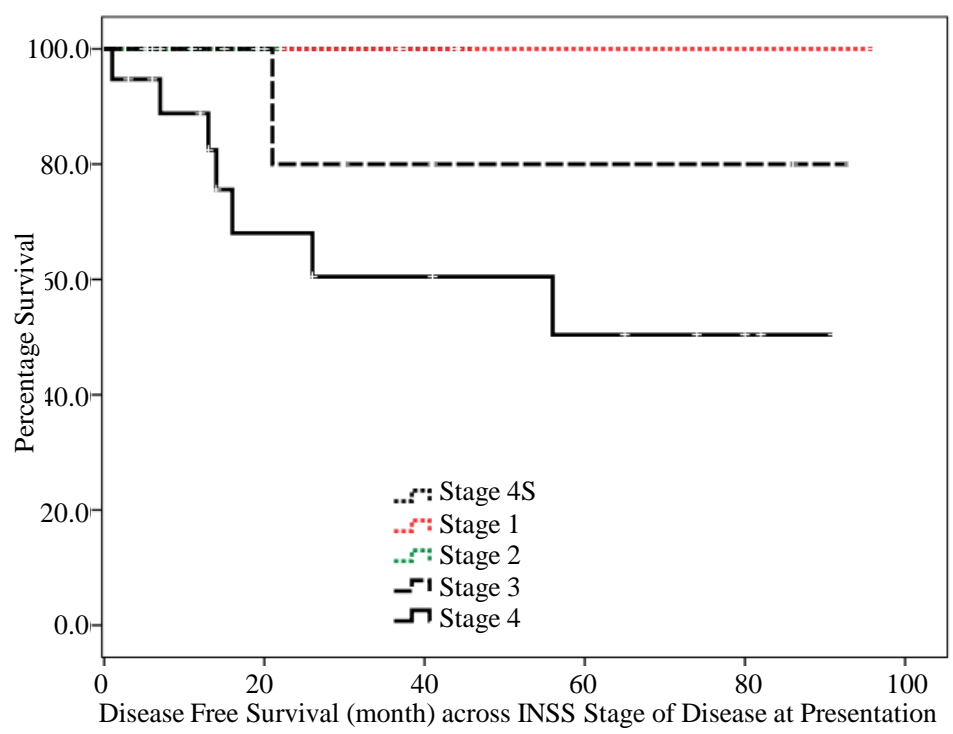

Figure 3. Disease free survival (month) across INSS stage of disease. 


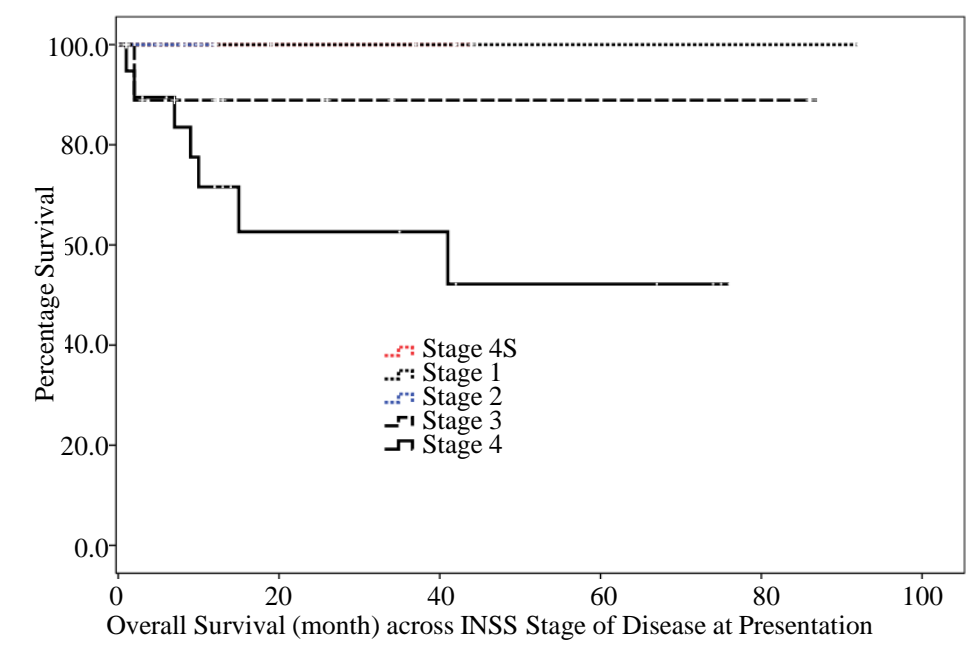

Figure 4. Overall survival (month) across INSS stage of disease.

\section{Discussion}

This study has provided important data concerning the epidemiology and clinicopathologic characteristics of Saudi Arabian children with Neuroblastoma and their expected survival. Several results are in agreement with findings from other international studies. Our cohort median age was 18.5 months, similar to the study by Papaioannou and McHugh [13], who concluded that most cases of aggressive Neuroblastoma present at younger age (median $<2$ yrs). Our survival data in relation to age is comparable to a large study in the USA done between 1975 and 2002 which showed the 5-year survival rate for Neuroblastoma in the United States has remained stable at approximately $87 \%$ for children younger than 1 year and has increased from $37 \%$ to $65 \%$ in children aged 1 to 14 years [14].

The EFS and OS rates of $66.5 \%$ and $71.5 \%$ respectively observed in this study is very comparable to that reported by Horner et al, where they noted the 5-year overall survival for all infants and children with Neuroblastoma has increased from 46\% when diagnosed between 1974 and 1989, to 71\% when diagnosed between 1999 and 2005 [15]. Our study also confirmed that low and intermediate risk Neuroblastomas have excellent survival rates, as is well known and reported in numerous studies [14]-[16] and that all patients with stage 1 NBL (4 patients) can be cured with surgery alone which is also supported by several studies [14].

An increased level of LDH proved to be a strong prognostic indicator of adverse outcome and correlated with unfavorable histopathology in several reports [17]-[19]. All our patients had LDH levels elevated above normal range, of which levels more than 5 times normal ( $\mathrm{LDH}>5 \mathrm{~N}$ ) were associated with the worst outcome. 13 patients had LDH $>5 \mathrm{~N}$, of whom 5 (38.5\%) died. In contrast, LDH $<5 \mathrm{~N}$ was found in 28 patients, of whom only 3 (11.7\%) died. Out of the 36 patients who had the MYCN assay, 10 patients had amplification (23.6\%), a finding that is slighter lower than the French Society of Pediatric Oncology study which reported an incidence of $37 \%$ [20]. We also did not find any statistically significant difference in outcome in comparison to the non-amplified group. This may well be explained by our small number of patients.

Our result showed a lower incidence of survival among patients with adrenal primary. This is comparable a large report from the International Neuroblastoma Risk Group Project, who analyzed more than 8000 children with NBL and Ganglioneuroblastoma (GNB) and reported a higher incidence of adrenal primary (47\%) and that adrenal sites were associated with inferior survival [18].

The prognosis of children who are older than one year with stage 4 remains poor, as seen in our study and other international studies, although it has significantly improved over the past two decades due to intensive treatment/supportive care approaches including autologous stem cell transplantation (ASCT). Our study finding of 55\% OS, is slightly higher than several studies and collaborative trials. Interestingly, although the majority of stage 4S NBL do well without chemotherapy [12], all our 4S cases (5 patients) had required chemotherapy. Of these four cases had symptomatic hepatomegaly, including two with severe respiratory distress who required mechanical ventilation and one with coagulopathy. The fifth patient had significant chylous ascites (post gross total resection). Four cases received 4 cycles of low risk, and the fifth had two cycles of chemotherapy. All pa- 
tients did very well. All patients who relapsed were stage 4 NBL and older than 1 year and none was salvageable. We could not collect sufficient data to accurately reflect on the incidence and severity of the late effects of Neuroblastoma survivors.

\section{Conclusion}

Our results showed a very comparable outcome to similar international cohorts, using a COG based treatment protocols, in support of the numerous publications and trials which confirmed the excellent outcome for stages 1 , 2, $3 \& 4 \mathrm{~s}$ and a dismal outcome for stage 4 in patients $>1$ yr old. We have set up a foundation for an excellent data base. Also the introduction of our formal comprehensive Long Term Follow up (LTFU) program will help in collecting comprehensive data regarding long term treatment effects, which will hopefully reflect on better understanding of our patients' cohort and also identify any unique features of the Saudi Arabian patients in comparison to international cohorts.

\section{Acknowledgements}

The authors gratefully acknowledge Ms. Penelope Swift (Penny) for her review the manuscript for editing.

\section{References}

[1] Brodeur, G.M. and Marris, J.M. (2006) Neuroblastoma. In: Pizzo and Poplack, B.G., Eds., Principles and Practice of Pediatric Oncology, 5th Edition, Lippincott Williams \& Wilkins, Philadelphia, 933-970.

[2] Matthay, K.K., Villablanca, J.G., Seeger, R.C., Stram, D.O., Harris, R.E., Ramsay, N.K., et al. (1999) Treatment of High-Risk Neuroblastoma with Intensive Chemotherapy, Radiotherapy, Autologous Bone Marrow Transplantation, and 13-Cisretinoic Acid. New England Journal of Medicine, 341, 1165-1173. http://dx.doi.org/10.1056/NEJM199910143411601

[3] Brodeur, G.M. (2003) Neuroblastoma: Biological Insights into a Clinical Enigma. Nature Reviews Cancer, 3, $203-216$. http://dx.doi.org/10.1038/nrc1014

[4] Maris, J.M. and Matthay, K.K. (1999) Molecular Biology of Neuroblastoma. Journal of Clinical Oncology, 17, 22642279.

[5] Gustafson, W.C. and Matthay, K.K. (2011) Progress towards Personalized Therapeutics: Biologic- and Risk-Directed Therapy for Neuroblastoma. Expert Review of Neurotherapeutics, 11, 1411-1423. http://dx.doi.org/10.1586/ern.11.103

[6] Canete, A., Gerrard, M., Rubie, H., et al. (2009) Poor Survival for Infants with MYCN-Amplified Metastatic Neuroblastoma Despite Intensified Treatment: The International Society of Paediatric Oncology European Neuroblastoma Experience. Journal of Clinical Oncology, 27, 1014-1019. http://dx.doi.org/10.1200/JCO.2007.14.5839

[7] Kerbl, R., Urban, C.E., Ambros, I.M., et al. (2003) Neuroblastoma Mass Screening in Infancy: Insights into the Biology of Neuroblastic Tumors. Journal of Clinical Oncology, 21, 4228-4234. http://dx.doi.org/10.1200/JCO.2003.10.168

[8] Schilling, F.H., Spix, C., Berthold, F., et al. (2002) Neuroblastoma Screening at One Year of Age. New England Journal of Medicine, 346, 1047-1053.

[9] Woods, W.G., Gao, R.N., Shuster, J.J., et al. (2002) Screening of Infants and Mortality Due to Neuroblastoma. New England Journal of Medicine, 346, 1041-1046. http://dx.doi.org/10.1056/NEJMoa012387

[10] Al-Mulhim, I. (1998) Neuroblastoma in Children: A 10-Year Experience in Saudi Arabia. Journal of Tropical Pediatrics, 44, 77-80. http://dx.doi.org/10.1093/tropej/44.2.77

[11] Fayea, N.Y., Atra, A.A., Khattab, T., Elimam, N.A., Felimban, S., Yousef, A., Basheer, A., Zayed, A., Baothman, A., Al-Sheikh, N. and Hussen, W. (2008) Outcome of Children Older than One Year with Neuroblastoma. Neurosciences (Riyadh), 13, 49-52.

[12] Elimam, N.A., Atra, A.A., Fayea, N.Y., Al-Asaad, T.G., Khattab, T.M., Al-Sulami, G.A. and Felimban, S.K. (2006) Stage 4S Neuroblastoma, a Disseminated Tumor with Excellent Outcome. Saudi Medical Journal, 27, 1734-1736.

[13] Papaioannou, G. and McHugh, K. (2005) Neuroblastoma in Childhood: Review and Radiological Findings. Cancer Imaging, 5, 116-127. http://dx.doi.org/10.1102/1470-7330.2005.0104

[14] Smith, M.A., Seibel, N.L., Altekruse, S.F., et al. (2010) Outcomes for Children and Adolescents with Cancer: Challenges for the Twenty-First Century. Journal of Clinical Oncology, 28, 2625-2634. http://dx.doi.org/10.1200/JCO.2009.27.0421

[15] Horner, M.J., Ries, L.A., Krapcho, M., et al. (2009) SEER Cancer Statistics Review, 1975-2006. National Cancer Institute, Bethesda. 
[16] Nuchtern, J.G., London, W.B., Barnewolt, C.E., et al. (2012) A Prospective Study of Expectant Observation as Primary Therapy for Neuroblastoma in Young Infants: A Children's Oncology Group Study. Annals of Surgery, 256, 573-580. http://dx.doi.org/10.1097/SLA.0b013e31826cbbbd

[17] Joshi, V.V., Cantor, A.B., Brodeur, G.M., et al. (1993) Correlation between Morphologic and Other Prognostic Markers of Neuroblastoma: A Study of Histologic Grade, DNA Index, N-Myc Gene Copy Number, and Lactic Dehydrogenase in Patients in the Pediatric Oncology Group. Cancer, 71, 3173-3181. http://dx.doi.org/10.1002/1097-0142(19930515)71:10<3173::AID-CNCR2820711045>3.0.CO;2-P

[18] Vo, K.T., Matthay, K.K., Neuhaus, J., London, W.B., Hero, B., Ambros, P.F., Nakagawara, A., Miniati, D., Wheeler, K., Pearson, A.D.J., Cohn, S.L. and DuBois, S.G. (2014) Clinical, Biologic, and Prognostic Differences on the Basis of Primary Tumor Site in Neuroblastoma: A Report from the International Neuroblastoma Risk Group Project. JCO, 56, 1621.

[19] Shuster, J.J., McWilliams, N.B., Castleberry, R., et al. (1992) Serum Lactate Dehydrogenase in Childhood Neuroblastoma: A Pediatric Oncology Group Recursive Partitioning Study. American Journal of Clinical Oncology, 15, 295-303. http://dx.doi.org/10.1097/00000421-199208000-00004

[20] Minard, V., Hartmann, O., Peyroulet, M.C., Michon, J., Coze, C., Defachelle, A.S., Lejars, O., Perel, Y., Bergeron, C., Boutard, P., Leverger, G., Stephan, J.L., Thyss, A., Chastagner, P., Couillault, G., Devalck, C., Lutz, P., Mechinaud, F., Millot, F., Plantaz, D., Rialland, X. and Rubie, H. (2000) Adverse Outcome of Infants with Metastatic Neuroblastoma, MYCN Amplification and/or Bone Lesions: Results of the French Society of Pediatric Oncology. British Journal of Cancer, 83, 973-979. http://dx.doi.org/10.1054/bjoc.2000.1412 